\title{
INVENTARISASI KUPU-KUPU DI UNIVERSITAS NEGERI MEDAN
}

\section{Inventory of Butterflies At State University of Medan}

\author{
Elida Hafni Siregar1), Halim Simatupang2) \\ Prodi Pendidikan Biologi Universitas Negeri Medan \\ jalan Willem Iskandar Pasar V Medan Estate \\ *Corresponding author: E-mail: elhafnis@gmail.com
}

\begin{abstract}
Abstrak
Penelitian ini bertujuan untuk mengetahui spesies kupu-kupu yang ditemukan di kampus Universitas Negeri Medan. Observasi dan koleksi kupu-kupu dilakukan di Universitas Negeri Medan pada bulan Maret-April 2016. Observasi kupu-kupu dilakukan ketika hari cerah mulai pukul 09.00 - 17.00 WIB dengan metode scan sampling. Dari hasil penelitian ini diperoleh sebanyak 43 spesies kupu-kupu yang termasuk kedalam 5 famili yaitu Pieridae, Papilionidae, Nymphalidae, Lycaenidae, dan Hesperiidae. 15 spesies kupu-kupu hanya ditemukan di satu lokasi, namun 2 spesies ditemukan pada semua lokasi, yaitu Appias olferna dan Papilio polytes.
\end{abstract}

Kata kunci: Appias olferna, Kupu-kupu, Papilio polytes, Universitas Negeri Medan

\begin{abstract}
This reseach aims to known the butterflies species at State University of Medan. Observation and collection of butterflies were conducted from March - April 2016 at State University of Medan. Butterflies observation conducted with scan sampling method at 09:00 to 17:00 in sunny days. This study consist of found 43 species of butterflies, belonging to 5 families, i.e. Pieridae, Papilionidae, Nymphalidae, Lycaenidae, and Hesperiidae. 15 species of butterflies are found in only one site but 2 species are found in all sites, i.e. Appias olferna and Papilio polytes.
\end{abstract}

Keywords: $\underline{\text { Appias }}$ olferna , butterfly, Papilio polytes, State University of Medan

How to Cite: Siregar, E.H. dan Simatupang, H. 2017, Inventarisasi Kupu-kupu di Universitas Negeri Medan, Jurnal BioLink, Vol.4 (1): Hal. 63-68 


\section{PENDAHULUAN}

Kupu-kupu termasuk salah satu spesies serangga yang merupakan anggota dari Filum Arthropoda, dan Ordo Lepidoptera. Kupu-kupu dicirikan dengan sayap yang ditutupi oleh sisik (lepidos = sisik; ptera $=$ sayap). Susunan sisik yang terdapat pada sayap seperti genting, memberi motif warna yang khas menurut spesiesnya (Elzinga 1978). Lepioptera dibagi menjadi dua subordo berdasarkan bentuk tubuh dan aktifitasnya, yaitu Rhopalocera (butterflies) yang aktif pada siang hari dan Heterocera (moth) yang aktif di malam hari (Corbet \& Pendlebury 1956). Jumlah kupu-kupu (butterflies) lebih sedikit dibandingkan ngengat namun lebih dikenal secara luas karena memiliki warna yang cerah dan menarik serta aktif pada siang hari dan (Peggie \& Amir 2006).

Penelitian tentang kupu-kupu telah banyak dilaporkan. Sutra dkk. (2012) melaporkan 42 spesies kupu-kupu yang ditemukan di Tanjung Balai Karimun dengan metode jala serangga, cylindrical gauze, dan umpan. Lima diantaranya merupakan spesies yang belum pernah dilaporkan terdapat di Sumatera. Spesies tersebut adalah Zeuxidia amethystus Butler, Euploea crameri C \& R. Felder, Arhopala avatha de Niceville, Euthalia mahadeva Fabricius, dan Lebadea martha Fruhstorfer.

\section{METODE PENELITIAN}

Penelitian dilakukan pada bulan Maret hingga April 2016, di Universitas Negeri Medan. Universitas Negeri Medan memiliki luas wilayah sebesar $546.661 \mathrm{~m}^{2}$, terletak di jalan Willem Iskandar Pasar $\mathrm{V}$ Medan Estate
Kecamatan Percut Sei Tuan Kabupaten Deli Serdang, Provinsi Sumatera Utara, berbatasan langsung dengan Kota Medan. Kampus ini berada pada titik koordinat $3^{\circ} 36^{\prime 29 "}$ Lintang Utara dan 9843'1" Bujur Timur. Pencuplikan sampel dilakukan pada lima lokasi yaitu di Fakultas Bahasa dan Seni, Fakultas Teknik, Fakultas Ilmu Sosial, Fakultas Ilmu Pendidikan, Fakultas Ilmu Keolahragaan, dan Fakultas Ekonomi.

\section{Observasi dan Koleksi Kupu-}

kupu. Observasi kupu-kupu dilakukan ketika hari cerah mulai pukul 09.00 17.00 WIB dengan metode scan sampling (Ratti dan Garton 1996). Untuk keperluan identifikasi beberapa kupukupu ditangkap dengan menggunakan jaring serangga. Kupu-kupu yang telah berhasil ditangkap dan dimatikan kemudian dimasukkan pada kertas papilot. Selanjutnya kertas papilot yg telah berisi spesimen kupu-kupu disimpan ke dalam wadah plastik dan diberikan silica gel dan kamfer.

Preparasi dan Identifikasi Kupukupu. Spesimen kupu-kupu yang telah disimpan di dalam wadah plastik kemudian dibawa ke laboratorium untuk diidentifikasi. Sebelum diidentifikasi, spesimen kupu-kupu terlebih dahulu direntangkan. Setelah direntangkan kupu-kupu dikeringkan dengan bantuan oven selama kurang lebih seminggu. Selanjutnya spesimen kupu-kupu siap untuk diidentifikasi. Identifikasi dilakukan berdasarkan Peggie dan Amir (2006) dan referensi lain yang relevan.

Analisis Data. Kupu-kupu yang diperoleh akan di deskripsikan dan dipaparkan sistematikanya. 


\section{HASIL DAN PEMBAHASAN}

Pada penelitian ini ditemukan 43 spesies kupu-kupu yang tersebar kedalam lima Famili yaitu Pieridae, Papilionidae, Nymphalidae, Lycaenidae, dan Hesperiidae. Spesies Appias olferna dan Papilio polytes ditemukan pada semua lokasi sampling. Namun ada 15 spesies yang hanya ditemukan di satu Tabel 1. Daftar kupu-kupu yang ditemukan di kampus Universitas Negeri Medan

\begin{tabular}{|c|c|c|c|c|c|c|c|}
\hline \multirow{2}{*}{ No Famili } & \multirow{2}{*}{ Spesies } & \multicolumn{6}{|c|}{ Lokasi ditemukan } \\
\hline & & FBS & FT & FIS & $\overline{\text { FIP }}$ & FIK & FE \\
\hline 1 Pieridae & Appias olferna & $\sqrt{ }$ & $\sqrt{ }$ & $\sqrt{ }$ & $\sqrt{ }$ & $\sqrt{ }$ & $\sqrt{ }$ \\
\hline 2 & Appias libythea & & & & & $\sqrt{ }$ & \\
\hline 3 & Catopsilia pomona & & & $\sqrt{ }$ & $\sqrt{ }$ & $\sqrt{ }$ & \\
\hline 4 & Catopsilia pyranthe & & & & $\sqrt{ }$ & & \\
\hline 5 & Delias hyparete & & $\sqrt{ }$ & $\sqrt{ }$ & $\sqrt{ }$ & & \\
\hline 6 & Eurema Blanda & $\sqrt{ }$ & $\sqrt{ }$ & & $\sqrt{ }$ & $\sqrt{ }$ & \\
\hline 7 & Eurema Alitha & $\sqrt{ }$ & $\sqrt{ }$ & & & & \\
\hline 8 & Eurema hecabe & $\sqrt{ }$ & $\sqrt{ }$ & & & $\sqrt{ }$ & \\
\hline 9 & Eurema sari & & & $\sqrt{ }$ & $\sqrt{ }$ & & \\
\hline 10 & Leptosia nina & $\sqrt{ }$ & $\sqrt{ }$ & & & & \\
\hline 11 Papilionidae & Graphium agamemnon & $\sqrt{ }$ & $\sqrt{ }$ & $\sqrt{ }$ & & & \\
\hline 12 & Graphium doson & $\sqrt{ }$ & $\sqrt{ }$ & $\sqrt{ }$ & & $\sqrt{ }$ & \\
\hline 13 & Papilio polytes & $\sqrt{ }$ & $\sqrt{ }$ & $\sqrt{ }$ & $\sqrt{ }$ & $\sqrt{ }$ & $\sqrt{ }$ \\
\hline 14 & Papilio memnon & $\sqrt{ }$ & $\sqrt{ }$ & & & & \\
\hline 15 & Pachliopta aristolochiae & & & $\sqrt{ }$ & & & \\
\hline 16 & Troides Helena & & & & $\sqrt{ }$ & & \\
\hline 17 Nymphalidae & Athyma nefte & & & $\sqrt{ }$ & $\sqrt{ }$ & $\sqrt{ }$ & \\
\hline 18 & Danaus chrysippus & & $\sqrt{ }$ & & & & \\
\hline 19 & Euploea mulcibar & $\sqrt{ }$ & $\sqrt{ }$ & $\sqrt{ }$ & $\sqrt{ }$ & & $\sqrt{ }$ \\
\hline 21 & Eoploea klugii & & $\sqrt{ }$ & & & & \\
\hline 22 & Euploea eunice & & $\sqrt{ }$ & & & $\sqrt{ }$ & $\sqrt{ }$ \\
\hline 23 & Euploea climea & & & & & & $\sqrt{ }$ \\
\hline 24 & Euthalia adonia & & & & & & $\sqrt{ }$ \\
\hline 25 & Hypolimnas bolina & $\sqrt{ }$ & $\sqrt{ }$ & $\sqrt{ }$ & & $\sqrt{ }$ & $\sqrt{ }$ \\
\hline 26 & Ideopsis juventa & $\sqrt{ }$ & $\sqrt{ }$ & & & & \\
\hline 27 & Ideopsis vulgaris macrina & $\sqrt{ }$ & $\sqrt{ }$ & & & & \\
\hline 28 & Ideopsis similis & & & & $\sqrt{ }$ & & \\
\hline 29 & Junonia atlites & $\sqrt{ }$ & $\sqrt{ }$ & & & & \\
\hline 30 & Junonia iphita & & & & & $\sqrt{ }$ & \\
\hline 31 & Junonia orithya & & & & & $\sqrt{ }$ & \\
\hline 32 & Melanitis leda & & $\sqrt{ }$ & & $\sqrt{ }$ & $\sqrt{ }$ & \\
\hline 33 & Mycalesis mineus & $\sqrt{ }$ & $\sqrt{ }$ & & & & \\
\hline 34 & Mycalesis horsfieldi & & $\sqrt{ }$ & $\sqrt{ }$ & & & \\
\hline 35 & Neptis hylas & $\sqrt{ }$ & $\sqrt{ }$ & & $\sqrt{ }$ & $\sqrt{ }$ & $\sqrt{ }$ \\
\hline 36 & Neptis columella & $\sqrt{ }$ & $\sqrt{ }$ & & $\checkmark$ & & \\
\hline 37 & Ypthima philomela & $\sqrt{ }$ & & & & & \\
\hline 38 & Ypthima horsfieldii & $\sqrt{ }$ & $\sqrt{ }$ & & & & \\
\hline 39 & Ypthima iarba & & & & & $\sqrt{ }$ & \\
\hline 40 Lycaenidae & Arhopala pseudocentaurus & $\sqrt{ }$ & & & & & \\
\hline 41 & Chilades pandava & $\sqrt{ }$ & & & & & \\
\hline 42 & Flos aniella & & & & $\sqrt{ }$ & & \\
\hline 43 Hesperiidae & Tagiades japetus & & & & & $\sqrt{ }$ & \\
\hline
\end{tabular}

lokasi, yaitu Appias libythea, Catopsilia pyranthe, Pachliopta aristolochiae, Troides Helena, Eoploea klugii, Euploea climea, Euthalia adonia, Ideopsis similis, Junonia iphita, Junonia orithya, Ypthima iarba, Arhopala pseudocentaurus, Chilades pandava, Flos aniella, dan Tagiades japetus (Tabel 1, Gambar 1). 
Siregar, E.H., dan Simatupang, H., Inventarisasi Kupu-kupu di Universitas Negeri Medan

Karakter yang dapat digunakan untuk membedakan kupu-kupu pada tingkat famili yaitu venasi sayap. Berdasarkan venasi sayapnya, kupukupu dapat dibedakan menjadi lima famili, yaitu Hesperidae, Papilionidae, Pieridae, Nymphalidae, dan Lycaenidae (Amir dkk. 2003). Famili Hesperidae dicirikan dengan ukuran lebar kepala sama atau lebih lebar dari toraks; memiliki 2 pasang spura pada tibia kaki belakang; segmen-segmen di ujung antenna menggada; ujung antenna membentuk kait dan jarak pada kedua pangkal antenna lebar; Radius sayap depan dengan bercabang 5 (R1, R2, R3, R4, R5), semua cabang berpangkal pada sel diskal (Amir dkk. 2003). Pada penelitian ini ditemukan satu spesies, yaitu Tagiades japetus.
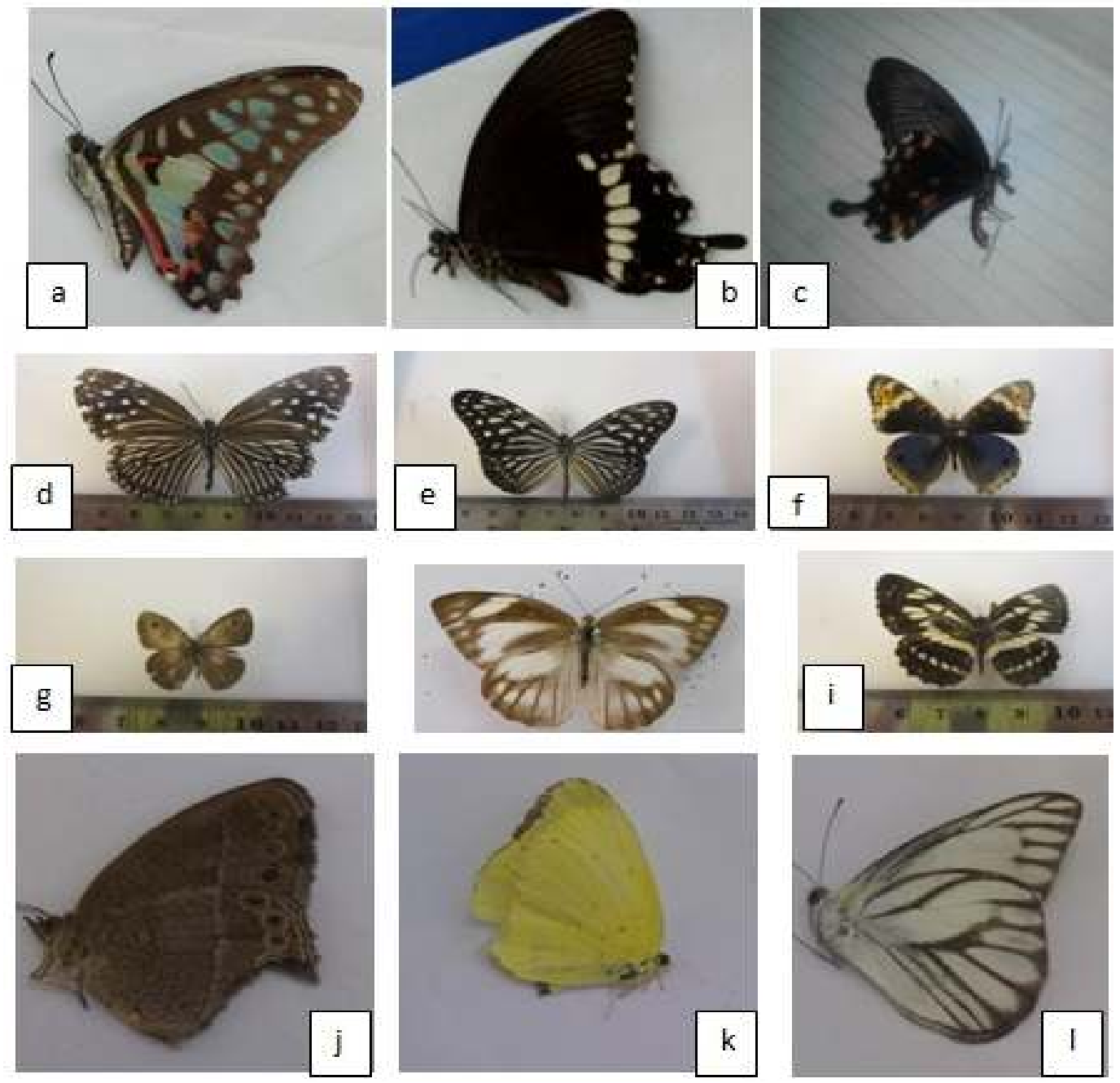

Gambar 1. Beberapa kupu-kupu yang ditemukan dikampus Universitas Negeri Medan. Graphium doson (a), Papilio polytes (b), dan Pachiliopta aristolochiae (c), Euploea mulciber (d), Ideopsis vulgaris (e), Junonia orythya (f), Neptis hylas (g), Appias libthea (h) Yphtima philomela (i) dan Mycalesis mineus (j). Eurema blanda (k), dan Appias ol 
Papilionidae: vena Radius pada sayap depan bercabang 5 (R1, R2, R3, R4, R5), Cubitus terlihat seperti bercabang 4, sayap belakang memiliki sebuah vena Anal (2A). beberapa spesies mempunyai pemanjangan sayap belakang seperti ekor (Amir dkk. 2003). Di Universitas Negeri Medan ditemukan enam spesies yang tersebar kedalam empat genus, yaitu Graphium, Papilio, Pachiliopta, dan Troides.

Pieridae: ukuran tubuh biasanya kecil sampai sedang, berwarna putih, kuning atau oranye dengan bercakbercak hitam. Sayap depan dengan Cubitus seperti bercabang 3, Radius dengan 3-4 cabang (R1, R2, R3, dan R4), Medius (M1) berpangkal pada cabang R, sayap belakang mempunyai 2 vena Anal (1A dan 2A). kaki depan normal atau sedikit mereduksi, cakar tarsus menggarpu (Amir dkk. 2003). Di Universitas Negeri Medan ditemukan sepuluh spesies yang tersebar kedalam lima genus, yaitu Appias, Catopsilia, Delias, Eurema, dan Letopsia.

Nymphalidae: ukuran dan warna tubuh sangat bervariasi. Kaki depan sangat mereduksi. Sayap depan relatif lebar, berbentuk segi tiga. Vena Radius bercabang 5 (R1, R2, R3, R4, R5), Cubitus tampak seperti bercabang 3, tidak memiliki vena Anal (3A). Sayap belakang dengan 2 vena Anal, vena humerus lurus atau bengkok pada ujungnya, sel diskal terbuka atau tertutup oleh vena halus. Pangkal vena tidak ada yang membengkak (Amir dkk. 2003). Di Universitas Negeri Medan ditemukan dua puluh dua spesies yang tersebar kedalam sebelas genus, yaitu Athyma, Danaus, Euploea, Euthalia, Hypolimnas, Ideopsis, Junonia,
Melanitis, Mycalesis, Neptis, dan Ypthima.

Anggota famili Nymphalidae paling banyak ditemukan pada penelitian ini, baik dari jumlah genus maupun spesies. Banyaknya jumlah spesies yang ditemukan dapatkan disebabkan karena ketersediaan sumber pakan untuk larvanya. Larva Nymphalidae mengkonsumsi pakan dari 26 famili tumbuhan (Sutra dkk. 2012). Diantaranya dari Famili Annonaceae, Malvaceae, Tiliaceae, Rutaceae, Sapindaceae, Anacardiaceae, Leguminoceae, Melastomataceae, Passifloraceae, Rubiaceae, Acanthaceae, Loranthaceae, Euphorbiaceae, dan Moraceae (Corbet and Pendlebury, 1956). Selain itu, Nymphalidae memiliki daerah persebaran yang luas, menyukai tempat terang, daerah ladang, hutan, dan juga menyukai buah busuk atau kotoran hewan (Sutra dkk. 2012).

Lycaenidae: berukuran kecil, lembut, umumnya berwarna cerah biru ungu. Pola venasi sayap hapir mirip dengan Pieridae, tetapi sayap depan dengan Medius (M1) tidak berpangkal pada cabang Radius sesudah diskal sel, Radius bercabang 4 (R1, R2, R3, dan R4). Sayap belakang dengan vena Humerus. Vena Costa (C) tidak menebal. Kaki depan kupu jantan mereduksi, cakar tarsus tidak menggarpu. Sayap belakang mempunyai tambahan seperti ekor (Amir dkk. 2003). Di Universitas Negeri Medan ditemukan tiga spesies yang tersebar kedalam lima genus, yaitu Arhopala, Chilades, dan Flos.

\section{SIMPULAN}

Kupu-kupu yang telah ditemukan dan diidentifikasi pada penelitian ini sebanyak 43 spesies di kelompokkan 
Siregar, E.H., dan Simatupang, H., Inventarisasi Kupu-kupu di Universitas Negeri Medan

kedalam 5 famili (Pieridae, Papilionidae,

Nymphalidae, Lycaenidae, dan

Hesperiidae). 15 spesies kupu-kupu

hanya ditemukan di satu lokasi namun 2

spesies ditemukan pada semua lokasi, yaitu Appias olferna dan Papilio polytes.

\section{DAFTAR PUSTAKA}

Amir M, Noerdjito WA, Kahono S. 2004. Kupu (Lepidoptera). Di dalam Muhammad Amir dan Sih Kahono, Editor. Serangga Taman Nasional Gunung Halimun Jawa Bagian Barat. Bogor (INA): BCP-JICA.

Corbet AS, Pendlebury HM. 1956. The Butterfly of Malaya Peninsula. London (UK): Oliver Boyd Edinburg.

Elzinga, R. J. 1987. Fundamentals of Entomology. New Delhi (IN): Prientice Hall of India, Private Limited.

Peggie D, Amir M. 2006. Practical guide to the Butterflies of Bogor Botanic Garden. Bogor (INA): LIPI.

Ratti JT, Garton EO. 1996. Research experimental design. Di dalam TA Bookhout, Editor. Research and Management Techniques for Wildlife and Habitats. Ed ke-5 (Revised). Kansas (US): Wildlife Society.

Sutra NSM, Dahelmi, Salmah S. 2012. Spesies Kupu-Kupu (Rhopalocera) Di Tanjung Balai Karimun Kabupaten Karimun, Kepulauan Riau. J. Bio. UA. 1(1): 35-44. 